\title{
Depressive Symptoms in Older People of San Vicente - Cape Verde (Africa)
}

\author{
Henrique Pereira ${ }^{2}$, Arminda Reis ${ }^{1}$, Rosa Marina Afonso², Graça Esgalhado ${ }^{2}$, Samuel Monteiro $^{2}$ and Manuel Loureiro $^{2}$ \\ ${ }^{1}$ University of Beira Interior \& University of Mindelo (Cape Verde), Portugal \\ ${ }^{2}$ University of Beira Interior, Portugal
}

"Corresponding author: Henrique Pereira, University of Beira Interior, Portugal, Tel: 35127531970; E-mail: hpereira@ubi.pt

Received Date: October 21, 2014, Accepted Date: November 28, 2014, Published Date: December 6, 2014

Copyright: (c) 2015, Henrique Pereira et al., This is an open-access article distributed under the terms of the Creative Commons Attribution License, which permits unrestricted use, distribution, and reproduction in any medium, provided the original author and source are credited.

\begin{abstract}
Depressive symptomatology has been identified as one of the most common psychiatric disorders in the elderly, and there is very little investigation in Cape Verde about this topic. The aim of this study was to assess depressive symptoms in the elderly in São Vicente - Cape Verde, aged 65 years and over. It is a cross-sectional descriptive study with a convenience sample. The instruments used were the Geriatric Depression Scale, the Katz index and a socio-demographic questionnaire. A sample of 204 elderly individuals participated in the study. The results indicate that $45.6 \%$ of respondents had no depression, $38.7 \%$ mild depression, and $15.7 \%$ had severe depression. In this study it was also observed that there is a higher incidence of depressive symptoms in women than in men, and among the elderly who are institutionalized compared to the non-institutionalized. The results suggest that depressive symptoms in elderly of São Vicente-Cape Verde- is a problem that needs more comprehensive studies to be able to devise strategies of intervention of this type of symptoms that reduce the longevity and quality of life of older people.
\end{abstract}

Keywords: Aging; Depression symptoms; Depression

\section{Introduction}

The aging of the population is of great interest globally, implying major challenges for society, for services and for individuals who grow older. The increasing incidence of neuropsychiatric disorders in the elderly population, including the cognitive decline, dementia and depression are the most common pathologies [1]. The growth of the older adult population in Africa demands more knowledge about their chronic health problems, such as depression [2]. The issue of aging in Cape Verde is an emerging issue for which are defined some policies and strategies. In 1995 the government presented a set of recommendations by the National Population Policy Statement, with the aim of carrying out a policy for seniors. However, the development of studies on how people age in Cape Verde seems to be an unexplored terrain, which calls for the need for research in this area so that strategies to promote quality of life elders of Cape Verde can be defined.

The cultural context of aging in Cape Verde differs from, for example, the European countries, because the elderly occupy a place of highest privilege. In Cape Verdean culture, it is considered that, in old age, people are holders of cultural and traditional values, and have extensive life experience, playing an important role in the education of grandchildren and performing household chores. The Cape Verdean society is also characterized by the principle of solidarity, well evidenced by the high number of elderly people economically dependent of other family members. However, the majority of older people from Cape Verde depend on their job, pension from the National Institute of Social Security, or a minimum social pension.

The aging process is often associated with losses at various levels, including social, economic, psychological and family. Examples of losses on the social network, for example loss of friends and family, loss of social roles, such as active worker, problems and changes in the level of health and physical appearance among others. However, the majority of older people are able to moderate the impact of this type of losses, changes or life events that may arise during the aging process $[3,4]$ and this is observed because of the fact that the subjective wellbeing in old age does not decrease[5]. However, there is a considerable proportion of older people who have difficulties in this stage of the life cycle, often developing in depressive symptoms.

It is very likely that depression is the leading cause of emotional distress at the end of life, decreasing significantly the quality of life of older people [6-8]. According to Blazer [9], a significant proportion of older people, for different reasons, have difficulties at meeting the demands of this phase of development and, often display depressive symptomatology.

However, depression in the elderly often not diagnosed due to its frequent atypical presentation and the fact that it's often presented with co morbidity with other disorders such as dementias, somatization, and low response to antidepressant medication or exacerbation of complaints associated with higher anxiety scores. Apart from major depressive disorder and dysthymia, many varieties of depression have been described as under-symptomatic and / or specific to the elderly [10].Another possible reason for underdiagnosis of depression among older people is the fact that, mistakenly professionals consider that sadness is a part of the aging process. Nonrecognition of depression in old age has several consequences, including compromised quality of life of the elderly and their families, poor prognosis, cognitive decline [11], increased risk of suicide [12] and mortality [13], and decreased physical capacity [14]. These consequences, in addition to compromising the quality of life and health of older people, hinder the provision of care for the elderly, often implying a greater need for formal care and institutionalization of the elderly.

Different studies on the incidence of depression in old age differ significantly in terms of results. Some studies point out to between 
Page 2 of 6

$15 \%$ and $30 \%$ [15]. Older people living in institutions tend to have higher rates of depression than elderly community residents. For example, Irigaray and Schneider found that the rate of elderly with depression living in the community is 4.8 to $14.6 \%$ and $22.0 \%$ in elderly people who are hospitalized or institutionalized. Some authors point out that among the elderly seeking medical treatment in outpatient facilities, in general, rates of depression range from $14 \%$ to $52 \%$, and that for the institutionalized elderly, the index ranges from $25 \%$ to $80 \%$ [16].

The disparity observed in the incidence of depression in old age in different studies can be related, among other factors, to the diversity of instruments used for assessing depressive symptoms in old age. For example, some authors choose specific instruments for depression in old age, such as the Geriatric Depression Scale [17]and others use scales or diagnostic criteria used for the general population. Although the depression in old age is an issue extensively investigated in western cultures, results on the incidence of depression in aging for all countries, including Cape Verde, isn't available.

According to the review of the literature we conducted, the topic of depressive symptoms in elderly of São Vicente - Cape Verde - is not investigated. Considering the relevance of this issue to promote the quality of life in old age, this study aims to: (1) assess depressive symptomatology in the elderly living in Sao Vicente - Cape Verde. We intend to further evaluate and compare depressive symptoms among the elderly: (2) males and females; (3) community-dwelling and institutionalized; (4) with reasonable and low socioeconomic status, and (5) with different levels of education. To this end we established the following hypothesis:

H1: Women present higher levels of depressive symptoms than men.

H2: Institutionalized participants present higher levels of depressive symptoms than participants who live in their communities.

H3: Participants with socioeconomic low status present higher levels of depressive symptoms than participants with reasonable socioeconomic status.

H4: Less educated participants present higher levels of depressive symptoms than more educated participants.

\section{Method}

\section{Participants}

A cross-sectional study was carried-out among a convenience sample of 204 elderly St. Vincent-Cape Verdians, 72 (35.3\%) were male and $132(64.7 \%)$ were female. Participants ranged between 65 and 97 years of age, mean age $=75$ years $(\mathrm{SD}=6.98) .59(28.9 \%)$ were aged between 65 to 70 years, $66(32.4 \%)$ between 71 and 76 years, 46 (22.5\%) between 77 and 82 years, 26 (12.7\%) between $83-88$ years, four (2.0\%) between $89-94$ years, and $3(1.5 \%)$ between 95 to 100 years. Information regarding socio-demographic data is shown in Table 1.

Regarding the perception that participants have of their health, the majority $(79.9 \%)$ of participants think that they have some pathology, and that they have reasonably good health $(61.8 \%)$. In Table 2 information concerning the general characterization and selfassessment of general health is systematized. Regarding the functionality of the participants, according to the results obtained by using the Katz index, most participants have high functionality levels, as shown in Table 3.

\begin{tabular}{|c|c|c|c|}
\hline & & $\mathrm{n}$ & $\%$ \\
\hline \multirow[t]{2}{*}{ Gender } & Male & 72 & $35.3 \%$ \\
\hline & Female & 132 & $64.7 \%$ \\
\hline \multirow[t]{3}{*}{ Age } & 65 to 70 years & 66 & $32.4 \%$ \\
\hline & 71 to 76 years & 46 & $22.5 \%$ \\
\hline & 77 to 95 years & 26 & $12.7 \%$ \\
\hline \multirow[t]{4}{*}{ Education } & Illiterate & 119 & $58.3 \%$ \\
\hline & Can read and write & 40 & $19.6 \%$ \\
\hline & Primary education & 41 & $20.1 \%$ \\
\hline & Secondary education & 4 & $2.0 \%$ \\
\hline \multirow[t]{5}{*}{ Marital status } & Married & 57 & $27.9 \%$ \\
\hline & Single & 78 & $38.2 \%$ \\
\hline & Widowed & 53 & $26.0 \%$ \\
\hline & Divorced/separated & 8 & $3.9 \%$ \\
\hline & Civil union & 8 & $3.9 \%$ \\
\hline \multirow[t]{5}{*}{ Income } & Pensioners & 104 & $51.0 \%$ \\
\hline & Family dependants & 36 & $17.6 \%$ \\
\hline & Retired & 38 & $18.6 \%$ \\
\hline & No income & 15 & $7.4 \%$ \\
\hline & Other & 11 & $5.4 \%$ \\
\hline \multirow[t]{2}{*}{ Work } & Not working & 195 & $95.6 \%$ \\
\hline & Working & 9 & $4.4 \%$ \\
\hline \multirow[t]{5}{*}{ Residence status } & Living with children & 100 & $49.0 \%$ \\
\hline & Living with other family members & 49 & $24.0 \%$ \\
\hline & Living alone & 29 & $14.2 \%$ \\
\hline & Living in a nursing home & 22 & $10.8 \%$ \\
\hline & Living with another person & 4 & $2.0 \%$ \\
\hline
\end{tabular}

Table 1: Socio-demographic Characteristics of the sample ( $\mathrm{N}=204)$

A Socio-demographic questionnaire was constructed for this study and included the assessment of the following variables: sex, age, education, marital status, perceived health, socioeconomic status, institutionalization and levels of autonomy.

The Geriatric Depression Scale (GDS) [17,18] was also used. This aims to assess depression in the elderly and provides a global depression indicator. It is a scale of self-assessment, and consists of 30 items with a "yes" and "no" answer format. It is considered that scores 0-10 indicate no depression, scores between 11-20 points suggest a slight depression, and between 21-30 points indicate severe depression. The GDS presented in this study a Cronbach's alpha 
Page 3 of 6

coefficient of 0.657 which indicates, according to DeVellis [19], an acceptable internal consistency of the instrument.

\begin{tabular}{|c|c|c|c|}
\hline & & $\mathrm{n}$ & $\%$ \\
\hline \multirow[t]{2}{*}{ Pathology } & Yes & 163 & $79.9 \%$ \\
\hline & No & 41 & $20.1 \%$ \\
\hline \multirow[t]{9}{*}{ Types of pathology } & Diabetes Mellitus & 55 & $27.0 \%$ \\
\hline & Obesity & 5 & $2.5 \%$ \\
\hline & Lung diseases & 19 & $9.3 \%$ \\
\hline & Hip fracture & 11 & $5.4 \%$ \\
\hline & Rheumatism & 133 & $65.2 \%$ \\
\hline & Visual Deficit & 153 & $75.0 \%$ \\
\hline & Oncologic pathology & 5 & $2.5 \%$ \\
\hline & Cardiovascular disease & 24 & $11.8 \%$ \\
\hline & Heart disease & 22 & $10.8 \%$ \\
\hline \multirow[t]{2}{*}{ Medication } & Yes & 138 & $67.6 \%$ \\
\hline & No & 66 & $32.4 \%$ \\
\hline \multirow{3}{*}{$\begin{array}{l}\text { Hospitalization in the } \\
\text { last year }\end{array}$} & Never & 147 & $72.1 \%$ \\
\hline & At least once & 45 & $22.1 \%$ \\
\hline & More than once & 12 & $5.9 \%$ \\
\hline \multirow[t]{5}{*}{ Health perception } & Very bad & 6 & $2.9 \%$ \\
\hline & Bad & 34 & $16.7 \%$ \\
\hline & Reasonable & 126 & $61.8 \%$ \\
\hline & Good & 33 & $16.2 \%$ \\
\hline & Very good & 5 & $2.5 \%$ \\
\hline
\end{tabular}

Table 2: General characteristics and perceived health $(\mathrm{N}=204)$

It was also used the Katz Index. This is a scale of Assessment of Activities of Daily Living. This instrument consists of questions about the person's ability to perform day-to-day tasks such as, for example, washing, dressing, using the toilet, move around, to be continent or feed him/herself. The scale consists of 18 items, with multiple choice answers. This scale allows characterizing the degree of autonomy / dependence of the individual in performing tasks inherent and necessary to their daily functioning.

\section{Procedures}

The study took place on the island of São Vicente, Republic of Cape Verde which is located $500 \mathrm{~km}$ from the West African coast. The project of this investigation, including documentation and tools, was sent to the National Research Ethics Committee for Health of Cape Verde, and was approved. The following applications for authorization to officers, directors and presidents of various institutions which held the collection of the data were made: Doctor Baptista de Sousa Hospital; Health Department; Nursing homes of the Red Cross; Social Development Centers of the island of São Vicente and the Cape
Verdean Association for Support of the Elderly. After the authorization of the institutions, we proceeded to a direct contact with the elderly, obtaining an informed consent from all study participants, to ensure all ethical procedures required for this type of work. A pilot application of the instruments to a group of 12 seniors who showed no difficulty in understanding the questions was made. The collection of data was done individually by face to face interviews. We opted for the oral application / reading of instruments in order to facilitate the implementation of instruments and facilitate understanding of the items, since the majority of participants was illiterate. Subsequently, data compilation, analysis and discussion of the results were made.

\begin{tabular}{|c|c|c|}
\hline & $\mathbf{N}$ & $\%$ \\
\hline Bathe without requiring any help & 174 & $\begin{array}{l}85.3 \\
\%\end{array}$ \\
\hline Only need assistance for washing one body part & 19 & 9.3 \\
\hline Need help to wash more than one body part & 11 & $5.4 \%)$ \\
\hline Choose clothes and dress themselves without needing help & 179 & $\begin{array}{l}87.7 \\
\%\end{array}$ \\
\hline only need help to tie their shoes & 14 & $6.9 \%$ \\
\hline $\begin{array}{l}\text { Need help to choose clothes and don't dress themselves } \\
\text { completely }\end{array}$ & 11 & $5.4 \%$ \\
\hline Use the toilet, clean up and put clothes on without any help & 177 & $\begin{array}{l}86.8 \\
\%\end{array}$ \\
\hline $\begin{array}{l}\text { Need help to go to the toilet, to clean up, put clothes on and to } \\
\text { use the potty at night }\end{array}$ & 17 & $8.3 \%$ \\
\hline Cannot use the toilet & 10 & $4.9 \%$ \\
\hline Into and out of bed, sit and stand unaided & 187 & $\begin{array}{l}91.7 \\
\%\end{array}$ \\
\hline Into and out of bed and sit, get up from the chair with help & 10 & $4.9 \%$ \\
\hline Do not get up from bed & 7 & $3.4 \%$ \\
\hline $\begin{array}{l}\text { Completely controls the anal sphincter and bladder, with no } \\
\text { losses }\end{array}$ & 177 & $\begin{array}{l}86.8 \\
\%\end{array}$ \\
\hline Occasional incontinence & 17 & $8.3 \%$ \\
\hline Incontinent or catheter use, requiring monitoring & 10 & $4.9 \%$ \\
\hline Eat without any help & 198 & $\begin{array}{l}97.1 \\
\%\end{array}$ \\
\hline Need help to cut food or spread the bread & 4 & $2.0 \%$ \\
\hline $\begin{array}{l}\text { Need help to eat, or is fed partly or wholly by tube or } \\
\text { intravenously }\end{array}$ & 2 & $1 \%$ \\
\hline
\end{tabular}

Table 3: Characterization of functionality of the participants $(\mathrm{N}=204)$ symptoms between groups $(\mathrm{N}=204)$, Note: ${ }^{*} \mathrm{p}<0,05$

\section{Statistical analysis}

Data analysis was performed with SPSS Statistics 19.0. Basic descriptive analysis and the internal consistency by Cronbach's alpha coefficient for the GDS scale were made. The normality of distribution was analyzed using the Kolmogorov-Smirnov test, yielding a p-value of 0.000 , is thus rejecting the null hypothesis, that is, the hypothesis of 
Page 4 of 6

the distribution is not normal. Assuming that the distribution is not normal, we used the Mann-Whitney $U$ test to test whether levels of depression among older people from different groups were significantly different or not.

\section{Ethical approval}

This study was approved by the scientific and ethical committees of the Research Unit of Health and Psychology (UIPES-ISPA, Institute of Applied Psychology in Portugal).

\section{Results}

Regarding depressive symptoms, results ranged from 1 to 27 points, with a mean of $12.53(\mathrm{SD}=6.35)$. The results indicate that 93 subjects (45.6\%) did not have depression, 79 (38.7\%) slight depression, and 32 (15.7\%) severe depression (Table 4).

The comparison between men and women, showed statistically significant differences $(\mathrm{z}=-1675, \mathrm{p}=0.000)$, with higher levels of depressive symptoms among women $(\mathrm{M}=13: 05, \mathrm{SD}=6.37)$ when compared to men $(\mathrm{M}=11.60, \mathrm{SD}=6.23)$ (Table 5).

\begin{tabular}{|l|l|l|}
\hline & $\mathrm{n}$ & $\%$ \\
\hline No depression & 93 & $45.6 \%$ \\
\hline Slight depression & 79 & $38.7 \%$ \\
\hline Severe depression & 32 & $15.7 \%$ \\
\hline
\end{tabular}

Table 4: Results for the assessment of levels of depression ( $\mathrm{N}=204)$

\begin{tabular}{|c|c|c|c|c|c|}
\hline & \multirow[b]{2}{*}{$\mathrm{N}$} & \multicolumn{2}{|c|}{ GDS Total } & \multirow[b]{2}{*}{ z } & \multirow[b]{2}{*}{$\mathrm{p}$} \\
\hline & & M & DP & & \\
\hline \multicolumn{6}{|l|}{ Gender } \\
\hline Female & $\begin{array}{l}13 \\
2\end{array}$ & 13.05 & 6.374 & -1.675 & $0.023^{*}$ \\
\hline Male & 72 & 11.60 & 6.232 & & \\
\hline \multicolumn{6}{|l|}{ Place of residence } \\
\hline Institutionalized & 22 & 16.68 & 5.669 & -3.508 & $0.022^{*}$ \\
\hline Not Institutionalized & $\begin{array}{l}18 \\
2\end{array}$ & 12.03 & 6.253 & & \\
\hline \multicolumn{6}{|l|}{ Economic status } \\
\hline Low income & $\begin{array}{l}13 \\
0\end{array}$ & 13.26 & 6.246 & -2.367 & $0.037^{*}$ \\
\hline $\begin{array}{l}\text { Reasonable or high } \\
\text { income }\end{array}$ & 74 & 11.32 & 6,369 & & \\
\hline \multicolumn{6}{|l|}{ Literacy } \\
\hline Illiterate & $\begin{array}{l}11 \\
9\end{array}$ & 13.74 & 6.44 & -3.197 & $0.006^{*}$ \\
\hline With instruction & 85 & 10.88 & 5.86 & & \\
\hline
\end{tabular}

Table 5: Results of the comparison of depressive
Concerning the comparison between institutionalized elderly participants and residents in the community, the results indicate that the average GDS score for institutionalized elderly was 16.68 $(\mathrm{SD}=5.66)$ and for the non-institutionalized it was $12: 03(\mathrm{SD}=6.25)$, which are statistically significant differences $(Z=-3,508, p=0.000)$.

A more detailed analysis of the results at the level of depressive symptoms according to the place of residence indicates that, of the 22 participants $(10.8 \%)$ living in nursing homes, three participants showed absence of depression, 11 showed mild depression, and 8 showed severe depression. As for the 149 (73.0\%) participants who reside with their children or other family members, the results indicate that $72(35.3 \%)$ did not experience depression, 60 (29.4\%) had mild depression, and 17 (8.4\%) severe depression.

Concerning the comparison of depressive symptoms among older adults with higher and lower economic statuses, the results indicate the existence of statistically significant differences $(z=-2367, p=0.000)$, showing that the elderly with lower economic resources have an average value of depressive symptoms $(M=13: 26, S D=6.24)$ higher than that of older people who have a more favorable situation regarding their economic situation $(\mathrm{M}=11: 32, \mathrm{SD}=6.36)$.

Regarding the level of education, when comparing the average levels of depressive symptoms among participants with and without instruction, the results indicate statistically significant differences $(\mathrm{z}=-3197, \mathrm{p}=0.000)$. The elderly illiterate participants have higher levels of depressive symptomatology $(M=13.74, S D=6.44)$ than the elderly who have some type of instruction $(\mathrm{M}=10.88, \mathrm{SD}=5.86)$.

\section{Discussion}

Taking as reference the generality of the results of different investigations on the incidence of depression in old age, data from this study brings attention to the high number of older people with depressive symptoms in this group of elderly respondents from $\mathrm{S}$. Vicente- Cape Verde. This study shows that $38.7 \%$ of participants have mild depression and $15.7 \%$ had severe depression. Considering, for example, the results of [20]which points out that, according to the review carried out for a prevalence of depressive symptoms in the elderly between $7.2 \%$ and $49 \%$, we find that the results observed in this study are in line with that observed in other countries, but higher than the results obtained by Thapain Ghana and South Africa where the prevalence of mild and severe depression was $6.7 \%$ and $2.7 \%$ respectively. This result is also higher than stated by different studies, particularly when indicated, for example, in the study of Maciel and War on the Brasilian northeast, indicating a prevalence of depressive symptoms of $25.5 \%$. The results of this study indicate that we need to analyze in more depth and in representative samples of the elderly population of Cape Verde the incidence of depression in old age to ascertain and discuss strategies for assessment and intervention for depression in old age. The high number of older people with depressive symptoms found in this study may, among other factors, be related to the fact that depression does not yet constitute a public health problem in Cape Verde which makes people devalue this important pathology that clearly compromises the quality of life and longevity in old age.

Based on $\mathrm{H} 1$ we can observe that the average of depressive symptomatology is higher in older men compared with older women. The elderly of S. Vicente - Cape Verde - participants in this study, $32.3 \%$ of women and $17.2 \%$ of male participants exhibit depressive symptoms. This result confirms the gender differences found in 
relation to depressive symptoms in the general population and in elderly populations. These results are somewhat similar to those found, with older people, which had found $30.1 \%$ for women and $15 \%$ for men results. The reasons underlying this gender difference discussed widely in the literature lie in biological, cultural and relational reasons, also observed in elderly men and women of Cape Verde. In addition to the causes of biological order that may underlie the psychosocial and cultural level, women are more easily allowed to take the sadness or despondency than men still tend to be associated with one gender role most associated with resistance and invulnerability before life and adversity.

With regard to depressive symptoms in institutionalized elderly, the literature review indicates that there higher depressive symptoms in elderly institutionalized subjects [21], when compared to elderly residing in the community [20]. Based on $\mathrm{H} 2$ we can observe that the results found in this sample of elderly Cape Verdeans corroborates the idea that the situation of institutionalization can be a predictor of onset and / or worsening of symptoms in cases of old age. It should be noted however that this difference between institutionalized and noninstitutionalized elderly was not observed in some studies [12]. Although the number of participants who were institutionalized in this study was low $(n=22)$ participated in this study almost all of the $S$. Vicente institutionalized elderly aged over 65 years. Thus, these results emphasize, once again, the institutional context of care for the elderly as a possible risk factor for the occurrence of depressive symptoms in old age. Although most elderly of S. Vicente - Cape Verde participants in this study, stay with relatives, $73.0 \%$ of participants live with their children or other family member, and institutional context seem little normative in the elderly Cape Verdean, these results deserve attention. The results emphasize the need for a thorough descriptive analysis of the user's profile of people who use such services in Cape Verde and contextual variables that may be related to the occurrence of depressive symptoms. Anticipating that the emerging aging population in Cape Verde can generate an increase in demand for such services, like is found in other countries, this work becomes essential for them in order to be seen as promoters of services to better the quality of life for the elderly dependent in Cape Verde.

Based on $\mathrm{H} 3$ and $\mathrm{H} 3$ we can observe that older people with more disadvantaged economic situation and with lower or no literacy levels which have more depressive symptoms, compared to elderly with better economic situation and more literacy. These results thus suggest that for the elderly surveyed in S. Vicente- Cape Verde, the contexts of greater economic vulnerability and information can directly or indirectly be associated with depressive symptoms in old age. This suggests that both the promoting of psychosocial interventions for better living conditions and access to information may be a strategy to promote mental health in old age.

\section{Conclusion}

In short, this study calls attention to the fact that in the group of elderly respondents from S.Vicente - Cape Verdea very significant presence of depressive symptoms was observed. Given the known implications of depressive symptoms in old age in compromising the quality and longevity in old age, these results call for the need for a thorough study of depressive symptoms in old age. As the aging population in Cape Verde is an emerging theme, it is considered that further analysis of this issue with the design and implementation of an epidemiological study could be an important basis for the work to devise policy interventions and promote active aging in Cape Verde.
Chronic illness, such as disability and depression among the aging population, is a growing public health concern in developing countries, including Cape Verde.

This study restricts generalizations, because it was done using a convenience sample. It will be important to analyze how to implement a population-based study or a representative sample of the population in future studies. Another important limitation relates to the instruments used. In Cape Verde the option is at the level of psychological assessment, to use of instruments Portuguese population, since Portuguese language is the official language. The scale used in this study, showed an acceptable internal consistency, however, the question of the appropriateness and psychometric scale used in the study population qualities puts up very urgently. It is recommended the construction and validation studies on instruments there are specific to the Cape Verdean population. Especially when it comes to elderly people, this is an important issue, given the cultural specificities of this group.

This is a pioneering study in Sao Vicente - Cape Verde, and this could be the starting point of a necessary work to alert to the need for a broader study regarding the rise of depressive symptoms and mental health in old age.

\section{References}

1. Soares E, deSouza-Rossignoli P (2014) Depression and Cognitive Decline: Factors Related to Demographics and Psycho Pharmacotherapy on Elderly in Nursing Homes. Journal of Psychiatry 17: 160.

2. Thapa SB, Martinez P, Clausen T(2014) Depression and Its Correlates in South Africa and Ghana among People Aged 50 and Above: Findings from the WHO Study on Global Ageing and Adult Health. Journal of Psychiatry 17.

3. Hardy S, Concato J, Gill TM (2002) Stressful life events among community-living older persons. Journal of General Internal Medicine 17: 841-847.

4. Hardy S, Concato J, Gill TM (2004) Resilience of community dwelling older persons. Journal of the American Geriatrics Society 52: 257-262.

5. Henchoz K, Cavalli S, Girardin M (2008) Health perception and health status in advanced old age: a paradox of association. Journal of Aging Studies 22: 282-290.

6. Barreto J, Leuschfner A, Santos F, Sobral M (2003) Escala de depressão geriátrica: Tradução portuguesa da Geriatric Depression Scale. In Escalas e testes na demência. Lisboa: Grupo Estudos de Envelhecimento Cerebral e Demências. No21/212/2003.

7. Paradela EMP, LourençoRA,Veras RP (2005) Validação da Escala de Depressão Geriátrica em um ambulatório geral. Revista de Saúde Pública 39: 918-923.

8. Stella F, Gobbi S, Corazza DI, Costa R. (2002) Depressão no idoso: Diagnóstico, tratamento e benefícios da actividade física. Motriz 8: 91-98.

9. Blazer DG (2003) Depression in Late Life: Review and Commentary. The Journals of Gerontology: Medical Sciences 58A: 249-265.

10. Spar JE, La Rue A (2005) Guia Prático Climepsi de Psiquiatria Geriátrica (1 ${ }^{\text {a }}$ Ed.). Lisboa: Climepsi Editores.

11. John P, Blandford AA, Strain LA (2006) Depressive symptoms among older adults in urban and rural areas. International Journal of Geriatric Psychiatry 21:1175-1180.

12. Costa A (2005) A depressão nos idosos portugueses. In Paúl C, Fonseca AM (Coords), Envelhecer em Portugal (pp.157-176). Lisboa: Climepsi.

13. Saz P, Dewey ME (2001)Depression, depressive symptoms and mortality in persons aged 65 and over living in the community: a systematic review of the literature. International Journal of Geriatric Psychiatry 19: 622-30. 
Citation: Pereira H, Reis A, Afonso RM, Esgalhado G, Samuel Monteiro, et al. (2015) Depressive Symptoms in Older People of San Vicente Cape Verde (Africa). J Psychiatry 18: 213. doi:10.4172/2378-5756.1000213

Page 6 of 6

14. Irigaray TQ, Schneider RH (2007) Características de personalidade e depressão em idosas da Universidade para a Terceira idade (UNITI/ UFRGS). Revista de Psiquiatria do Rio Grande do Sul 29: 169-175.

15. Maciel ACC, Guerra RO (2006) Prevalência e factores associados à sintomatologia depressiva em idosos residentes no Nordeste Brasil. Jornal Brasileiro de Psiquiatria 55: 26-33.

16. Fernandes MGM, Nascimento NFS, Costa KNFM (2010) Prevalência e determinantes de sintomas depressivos em idosos atendidos na atenção primária de saúde. Revista da Rede de Enfermagem do Nordeste 11: 19-27.

17. Yesavage JA, Brink TL, Rose TL, Lum O, Huang V, Adey, Leirer VO (1983) Development and Validation of a Geriatric Depression Screening Scale: A Preliminary Report. Journal of Psychiatric Research 17: 37-49.
18. Faria ACNB, Barreto SM, Passos MA. (2008) Sintomatologia depressiva em idosos de um plano de saúde. Revista Médica de Minas Gerais18: 175-182.

19. DeVellis RF (1991). Scale development: Theory and applications. Newbury Park, CA: Sage Publications.

20. Djernes, J K (2006) Prevalence and predictors of depression in populations of elderly: a review. Acta Psychiatr Scand 113: 372-87.

21. Leal MCC, Apóstolo JLA, Mendes AMOC, Marques APO (2014)Prevalence of depressive symptoms and associated factors among institutionalized elderly. Acta Paulista de Enfermagem 27: 44-47. 